\title{
Aspectos biológicos e morfológicos de Rothschildia aurota speculifera (Walker) (Lepidoptera: Saturniidae): uma mariposa diapausante
}

\author{
Géssyca Bispo de Oliveira Lima * \\ Gabriel Vila-Verde \\ Kleberson dos Santos Duarte \\ Rozimar de Campos Pereira \\ Márlon Paluch \\ Universidade Federal do Recôncavo da Bahia \\ Laboratório de Sistemática e Conservação de Insetos, Setor de Ciências Biológicas \\ Rua Rui Barbosa, 710, Centro, CEP 44380-000, Cruz das Almas - BA, Brasil \\ * Autor para correspondência \\ gessyca.gsl@gmail.com
}

Submetido em $07 / 10 / 2020$

Aceito para publicação em 16/02/2021

\section{Resumo}

O gênero Rothschildia Grote, 1897 apresenta ampla distribuição geográfica nas Américas. O gênero é representado por 36 espécies sendo que 14 são encontradas no Brasil. Este estudo descreve a biologia e morfologia externa dos estágios imaturos e o acompanhamento do estágio pupal de Rothschildia aurota speculifera (Walker, 1855). A quetotaxia da cabeça de primeiro ínstar, e os estágios de ovo e pupa são comparados com outras espécies de Saturniidae pertencentes à Hemileucinae, Ceratocampinae e Saturniinae, e o ciclo de vida e comportamento com ao de outras espécies de Rothschildia. O estágio de ovo teve duração de 12-14 dias, larval de 34-39 dias; pré-pupa e pupa totalizaram 37-632 dias. A duração do último estágio imaturo indica que esta subespécie é diapausante. Cinco ínstares foram confirmados pela regra de Dyar, com uma taxa de crescimento de $\mathrm{K}=1,4$.

Palavras-chave: Ciclo de vida; Mata Atlântica; Planta hospedeira; Quetotaxia

\section{Abstract}

Biological and morphological aspects of Rothschildia aurota speculifera (Walker) (Lepidoptera: Saturniidae) a diapausante moth. The genus Rothschildia Grote, 1897 presents broad geographical distribution in the Americas. The genus is represented by 36 species and 14 which found in Brazil. This study describes the biology, external morphology of the immature stages and the monitoring of the pupal stage of Rothschildia aurota speculifera (Walker, 1855). The first instar head chaetotaxy, egg and pupa stages are compared with other Saturniidae species belonging to Hemileucinae, Ceratocampinae, and Saturniinae and the natural history with other Rothschildia species. The egg stage had duration of 12-14 days, larval 34-39 days; pre-pupa and pupa totaled 37-632 days. The duration of last immature stage indicates that this subspecies is diapausante. Five instars were confirmed by the Dyar rule, with a growth rate of $\mathrm{K}=1.4$.

Key words: Atlantic Forest; Chaetotaxy; Host plant; Life cycle 


\section{Introdução}

A família Saturniidae, apesar de cosmopolita, é predominante nas regiões tropicais do Novo Mundo, no Brasil compreende cerca de 500 espécies agrupadas em cinco subfamílias: Arsenurinae, Ceratocampinae, Hemileucinae, Oxyteninae e Saturniinae (DUARTE et al., 2012; ALBERTONI et al., 2018).

O gênero Rothschildia Grote, 1897 (Saturniinae) possui 36 espécies, destas 11 foram recentemente descritas para as Américas (México, Costa Rica, Trinidad e Tobago, Colômbia, Equador, Peru e Argentina) (LEMAIRE, 1996; BRECHLIN; MEISTER, 2012; 2013). Para o Brasil são conhecidas 14 espécies, das quais seis são frequentemente registradas nas regiões sul e sudeste: Rothschildia arethusa (Walker, 1855); Rothschildia aurota speculifera (Walker, 1855); Rothschildia belus (Maassen, [1873]); Rothschildia hesperus betis (Walker, 1855); Rothschildia hopfferi (C. Felder \& R. Felder, 1859) e Rothschildia jacobaeae (Walker, 1855) (LEMAIRE, 1978; 1996; NUNES et al., 2004; SIEWERT et al., 2010; SANTOS et al., 2015; ALBERTONI et al., 2018).

De acordo com Lemaire (1996), para R. aurota (Cramer, 1775) são consideradas apenas duas subespécies. A distribuição conhecida para $R$. a aurota (Cramer, 1775) compreende o bioma amazônico no Suriname e Guiana Francesa e na Amazônia Andina no Peru e Bolívia (LEMAIRE, 1996; WENCZEL; NAUMANN, 2005; INPN, 2020). Rothschildia a. speculifera é considerada de ampla distribuição geográfica no Brasil, habitando diferentes fitofisionomias da Mata Atlântica nos estados de São Paulo, Paraná, Santa Catarina e Rio Grande do Sul (NUNES et al., 2004; SIEWERT et al., 2010; SANTOS et al., 2015; ALBERTONI et al., 2018).

A maioria dos trabalhos de biologia e morfologia de estágios imaturos de Saturniinae na região Neotropical foi realizada com espécies de Hemileucinae (WOLFE; BALCÁZAR-LARA, 1994; ZANUNCIO et al., 1994; FURTADO, 2002; SPECHT et al., 2006a; 2006b; 2007a; 2007b; 2009; 2010; 2011; 2012; ZENKER et al., 2013; MORAES et al., 2017; GONÇALVES et al., 2020), e poucas de outras subfamílias como Arsenurinae, Almeidaia aidae Mielke \& Casagrande, 1981
(FURTADO, 2004) e Ceratocampinae, Adeloneivaia fallax (Boisduval, 1872) (ALBERTONI; DUARTE, 2015). Para Saturniinae, Rougerie e Estradel (2008) publicaram um estudo morfológico detalhado dos estágios imaturos de Bunaeopsis licharbas (Maassen \& Weyding, 1885), uma espécie com ampla distribuição no continente africano "African Emperor Moth". No Neotrópico, os estudos para Saturniinae são antigos e relacionados principalmente ao gênero Rothschildia, onde Urban e Oliveira (1972) analisaram a biologia de $R$. jacobaeae, Oliveira e Urban (1987) de $R$. h. betis e Amarillo-S e Wolfe (1997) apresentaram ciclo de vida de Rothschildia zacateca (Westwood, [1854]).

Desta forma, com intuito de ampliar os conhecimentos relacionados ao ciclo de vida e sistemática de Saturniinae, foi realizado um estudo da biologia e morfologia dos estágios imaturos com acompanhamento do período de diapausa de $R$. $a$. speculifera, uma mariposa frequentemente registrada na Mata Atlântica.

\section{Material e Métodos}

Insetos adultos e pupas em casulos foram coletados em um fragmento urbano de Mata Atlântica, área de proteção ambiental municipal "Mata de Cazuzinha" em Cruz das Almas, Bahia. Os casulos foram encontrados em ramos de Schinus terebinthifolius Raddi (Anacardiaceae), que, segundo Hosts (2020), é uma das plantas hospedeiras de $R$. aurota.

Os estágios imaturos foram acompanhados em gaiolas de $80 \mathrm{~cm}^{3}$ compostas por faces de tecido voil linho branco e arestas em tubos de PVC $22 \mathrm{~mm}$ sobre bancadas de granito. Os estágios de ovo e larval foram monitorados em laboratório e os dados de temperatura e umidade registrados diariamente com termo-higrômetro digital. O estágio pupal foi submetido a condições ambiente de casa de vegetação, e os dados abióticos obtidos junto ao CPTEC/INPE (Centro de Previsão de Tempo e Estudos Climáticos/Instituto Nacional de Pesquisas Espaciais).

Ovos foram obtidos de uma fêmea fecundada em cativeiro. Folhas de S. terebinthifolius foram oferecidas 
como substrato para oviposição. Ovos foram mantidos na gaiola até a eclosão das larvas. Posteriormente, cada ramo da planta hospedeira recebeu um grupo de oito larvas, a planta foi mantida fresca com inserção basal dos galhos em frascos com água, que foi substituída a cada três dias entre o primeiro e terceiro ínstar, dois dias no quarto ínstar e diariamente no quinto ínstar.

As pré-pupas, nos casulos, foram etiquetadas com a data de formação e transferidas para gaiolas. Os casulos foram suspensos em placas verticais de isopor onde foram mantidos em condições ambientais até a emergência dos adultos.

Exemplares representativos de todas as fases do desenvolvimento foram fixados e depositados no acervo da Coleção Entomológica do Laboratório de Sistemática e Conservação de Insetos, Setor de Biologia, Centro de Ciências Agrárias, Ambientais e Biológicas, Universidade Federal do Recôncavo da Bahia, Cruz das Almas, BA. As mensurações de comprimento no estágio larval foram feitas com os espécimes vivos em repouso. Ovos, larvas de primeiro e segundo ínstares e cápsulas cefálicas foram analisados em microscópio estereoscópico trinocular SZX7 Olympus acoplado à câmera de vídeo digital SC30 e software cellSens Imaging. Ilustrações morfológicas foram realizadas com microscópio estereoscópico Leica com câmara clara acoplada.

Para determinação dos ínstares, foi empregada a análise de razão de crescimento, regra de Dyar, utilizando a média da maior largura da cápsula cefálica de cada ínstar (PARRA; HADDAD, 1989). Os termos empregados para morfologia foram embasados em García-Barros e Martin (1995) para estágio de ovo, Stehr (1987) para quetotaxia do primeiro ínstar e estágio larval, e Mosher (1916) para o estágio pupal.

\section{Resultados}

\section{Ciclo de vida e comportamento}

A duração do estágio de ovo foi de 12-14 dias em temperatura média de $22,8 \pm 2,4^{\circ} \mathrm{C}$ e umidade média de $67,3 \pm 7,5 \%$. A oviposição ocorreu junto à superfície interna das paredes da gaiola e no pecíolo e folíolos das folhas de $S$. terebinthifolius. A oviposição pode ocorrer em fileiras de 3-9 ovos postos lado a lado, sendo mais frequente o grupo de sete e oito ovos. Também ocorreram oviposições isoladas, dois ovos juntos, fileiras duplas com 9-10 ovos e aglomerados irregulares de até 19 ovos. O número máximo de ovos obtidos de uma única fêmea foi de 285 e foram ovipositados em um período de aproximadamente $48 \mathrm{~h}$.

A duração do estágio larval foi de 34-39 dias em temperatura média de $23,6 \pm 2,2^{\circ} \mathrm{C}$ e umidade média de 65,8 $\pm 7,4 \%$. Rothschildia a. speculifera se mostrou levemente urticante a partir do terceiro ínstar, entretanto, nos dois últimos, a intensidade aumentou significativamente. $\mathrm{O}$ primeiro ínstar teve duração de seis dias em temperatura média de $23,1 \pm 2,8^{\circ} \mathrm{C}$ e umidade média de $64,8 \pm 9,1 \%$. Segundo instar, de cinco dias em temperatura média de $22,4 \pm 1,84^{\circ} \mathrm{C}$ e umidade média de 70,2 $\pm 4,5 \%$. Terceiro instar, de seis dias em temperatura média de $24 \pm 1,5^{\circ} \mathrm{C}$ e umidade média de 65,3 $\pm 4,7 \%$. Quarto instar, de seis dias em temperatura média de $24,2 \pm 2,1^{\circ} \mathrm{C}$ e umidade média de $63,1 \pm 7,3 \%$. Quinto ínstar teve variação de 11-16 dias em temperatura média de $23,7 \pm 2,1^{\circ} \mathrm{C}$ e umidade média de $66 \pm 7,8 \%$. As larvas de primeiro ínstar, ao eclodir, se alimentaram parcialmente do cório, apenas o suficiente para saída do ovo. O primeiro e o segundo ínstares se mantiveram gregários. Do terceiro ao quarto ínstar o gregarismo diminuiu, podendo encontrar larvas isoladas, e, no quinto, quando assumiram o maior tamanho e peso, foram encontradas isoladas nos ramos apicais da planta hospedeira. Não houve raspagem do parênquima foliar, a folha foi consumida por completo desde o primeiro ínstar.

A duração do estágio pupal, incluindo o período de pré-pupa, foi de 37-632 dias. A duração média para fêmeas foi de 255,6 $\pm 103,6$ dias e para machos de $275,5 \pm 124,3$ dias. A fêmea que alcançou o maior período de diapausa correspondeu a 494 dias e o macho 632 dias. Ao todo foram acompanhadas 75 pupas, destas 67 completaram o desenvolvimento, 36 machos e 31 fêmeas, resultando em $9 \%$ de mortalidade. O estágio pupal se iniciou no final de agosto de 2017 e na primavera ocorreram as primeiras emergências 
$(\mathrm{N}=3)$, com duração de $66 \pm 38,2$ dias. No ano de 2018 ocorreram $90 \%$ das emergências distribuídas nas quatro estações do ano, verão $(\mathrm{N}=24)$, duração de 183 $\pm 17,8$ dias, outono $(\mathrm{N}=19)$, duração de $247,5 \pm 24,3$ dias, inverno $(\mathrm{N}=10)$, duração de 323,2 \pm 5,6 dias e primavera $(\mathrm{N}=7)$, duração de $457 \pm 13,8$ dias. Durante o ano de 2019 houve a emergência de dois machos e uma fêmea no verão, com duração de $494 \pm 1,7$, e um macho no terço final do outono (Figura 1).

\section{Descrição dos estágios imaturos}

\section{Estágio de ovo}

Ovo. Tipo achatado, esférico levemente alongado, possui eixo micropilar paralelo ao substrato, micrópila pouco diferenciada, exocório esbranquiçado, opaco, esculturado em uma rede densa de células contíguas. Maior diâmetro 2,4 $\pm 0,1 \mathrm{~mm}$ e menor $1,8 \pm 0,15 \mathrm{~mm}$ $(\mathrm{N}=32)$ (Figura 2A; 2B).

\section{Estágio larval}

Primeiro ínstar. Comprimento total em repouso de $10 \pm 0,6 \mathrm{~mm}(\mathrm{~N}=20)$. Cápsula cefálica largura máxima 1,3 $\pm 0,1 \mathrm{~mm}(\mathrm{~N}=20)$. Cabeça lisa, arredondada com sutura epicranial equivalente a um terço das suturas adfrontais. Cabeça com aspecto geral castanho escuro, mas com porção anterior, frontoclípeo e labro amarelados. Tórax com placa protorácica amarela e pernas castanhas; escolos amarelos; faixas dorsolaterais pretas e amarelas; porção láteroventral esbranquiçada. Abdome segue o mesmo padrão do tórax; larvópodos com placas laterais castanhas. Presença de cerdas castanhas distribuídas na cabeça, placa protorácica, pernas, escolos e placas dos larvópodos. Espiráculos esbranquiçados, peritrema castanho, T1 e A8 maiores que A1-A7 (Figura 2C; 2D; 2E).

Quetotaxia da cápsula cefálica. Apresenta cerdas primárias longas e ausência de cerdas secundárias. O plano básico frontal equivale a 14 pares de cerdas primárias e cinco pares de poros, excluindo as peças bucais. Presença de oito grupos de cerdas táteis e longas: anterior (A1, A2 e A3), estemal (S1 e S2), subestemal (SS2), lateral (L1), póstero-dorsal (P1 e P2), adfrontal (AF1 e AF2), frontal (F1) e clipeal (C1 e C2). Frontoclípeo com cerda F1 próxima ao clípeo abaixo do poro Fa. Clípeo com cerdas $\mathrm{C} 1$ próximas à sutura adfrontal e $\mathrm{C} 2$ mais interna. Cerda AF1 ao lado da porção mediana da sutura adfrontal. Cerda AF2 ao lado da porção superior da sutura adfrontal. Cerda S1 ao lado do terceiro estema, S2 ao lado do primeiro estema. Subestematal SS2 acima do quinto estema. Poro AFa

FIGURA 1: Distribuição da emergência de machos e fêmeas de Rothschildia aurota speculifera, média mensal da temperatura (mínima, máxima e média) e umidade durante sete estações (da primavera 2017 ao outono 2019) no município de Cruz das Almas, BA.

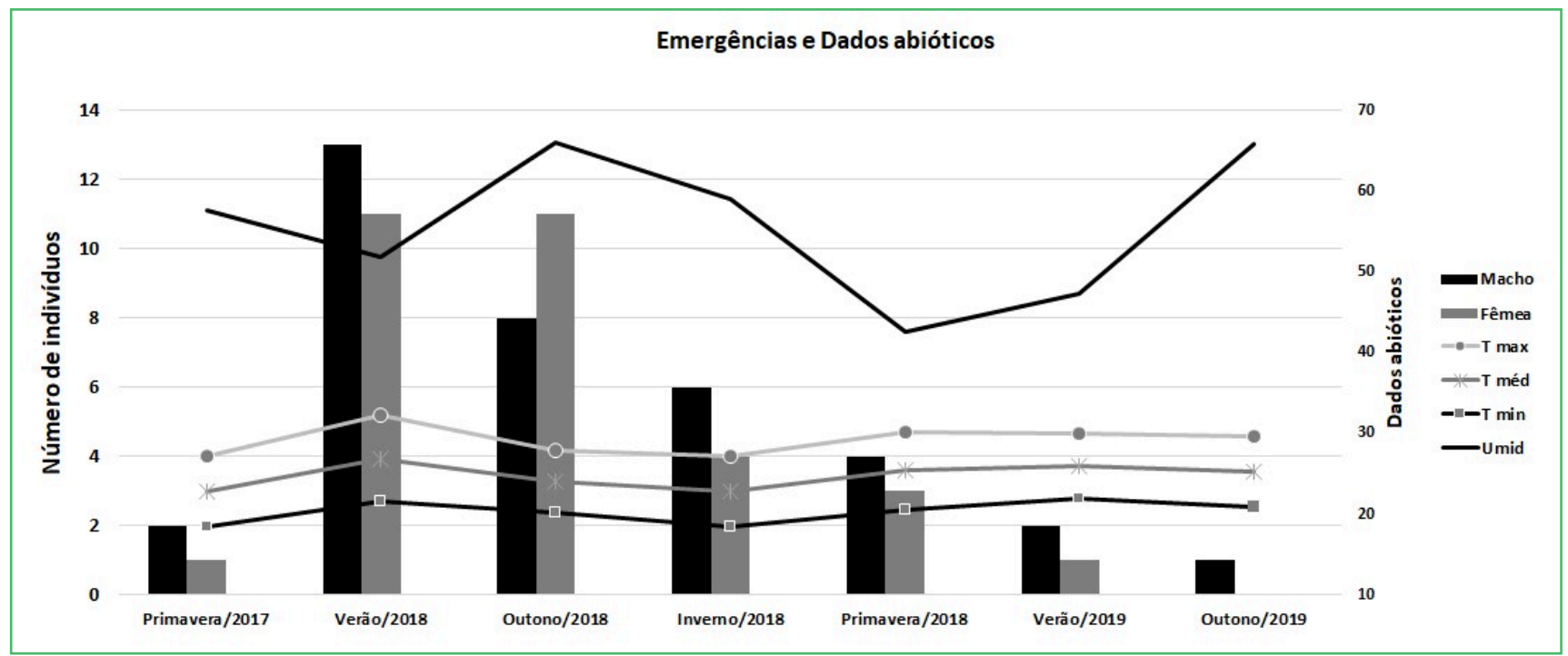


ao lado da junção entre sutura epicraniana e adfrontal, $\mathrm{Pb}$ entre as cerdas $\mathrm{P} 1$ e $\mathrm{P} 2$, Aa entre a triangulação das cerdas A1, A2 e A3, Sb ao lado do quarto estema e Fa acima da cerda F1. Labro com cerdas L1, L2 e L3 em arranjo linear na porção lateral, e M1, M2 e M3 na porção mediana dos lobos, em triangulação com a M1 mais interna. Mandíbula com duas cerdas laterais (Figura 2F).

Segundo ínstar. Comprimento total em repouso de $14,3 \pm 1,1 \mathrm{~mm}(\mathrm{~N}=20)$. Cápsula cefálica largura máxima
$1,9 \pm 0,1 \mathrm{~mm}(\mathrm{~N}=21)$. Cabeça com aspecto geral castanho escuro, mas com porção anterior, frontoclípeo e labro amarelados. Tórax e abdome mesmo padrão do ínstar anterior com tonalidades mais escuras (Figura 2G).

Terceiro ínstar. Comprimento total em repouso de $25,6 \pm 1,1 \mathrm{~mm}(\mathrm{~N}=20)$. Cápsula cefálica largura máxima $2,7 \pm 0,1 \mathrm{~mm}(\mathrm{~N}=25)$. Cabeça com aspecto geral castanho escuro, mas com porção anterior, frontoclípeo e labro esverdeados. Tórax com placa protorácica verde;

FIGURA 2: Rothschildia aurota speculifera. (A) Ovos em pecíolo de Schinus terebinthifolius. (B) Ovos em folíolo de S. terebinthifolius. (C) Larvas de 1ํ ínstar, aspecto do gregarismo e alimentação. (D) Larva de 1ํ ínstar, vista dorsal. (E) Larva de 1ำ ínstar, vista lateral. (F) Larva de 1 ínstar, vista frontal quetotaxia da cabeça. (G) Larva de 2o ínstar, vista dorsal. (H) Larva de 3 ínstar, vista dorsal. (I) Larva de 3 o ínstar, vista dorsal-lateral.
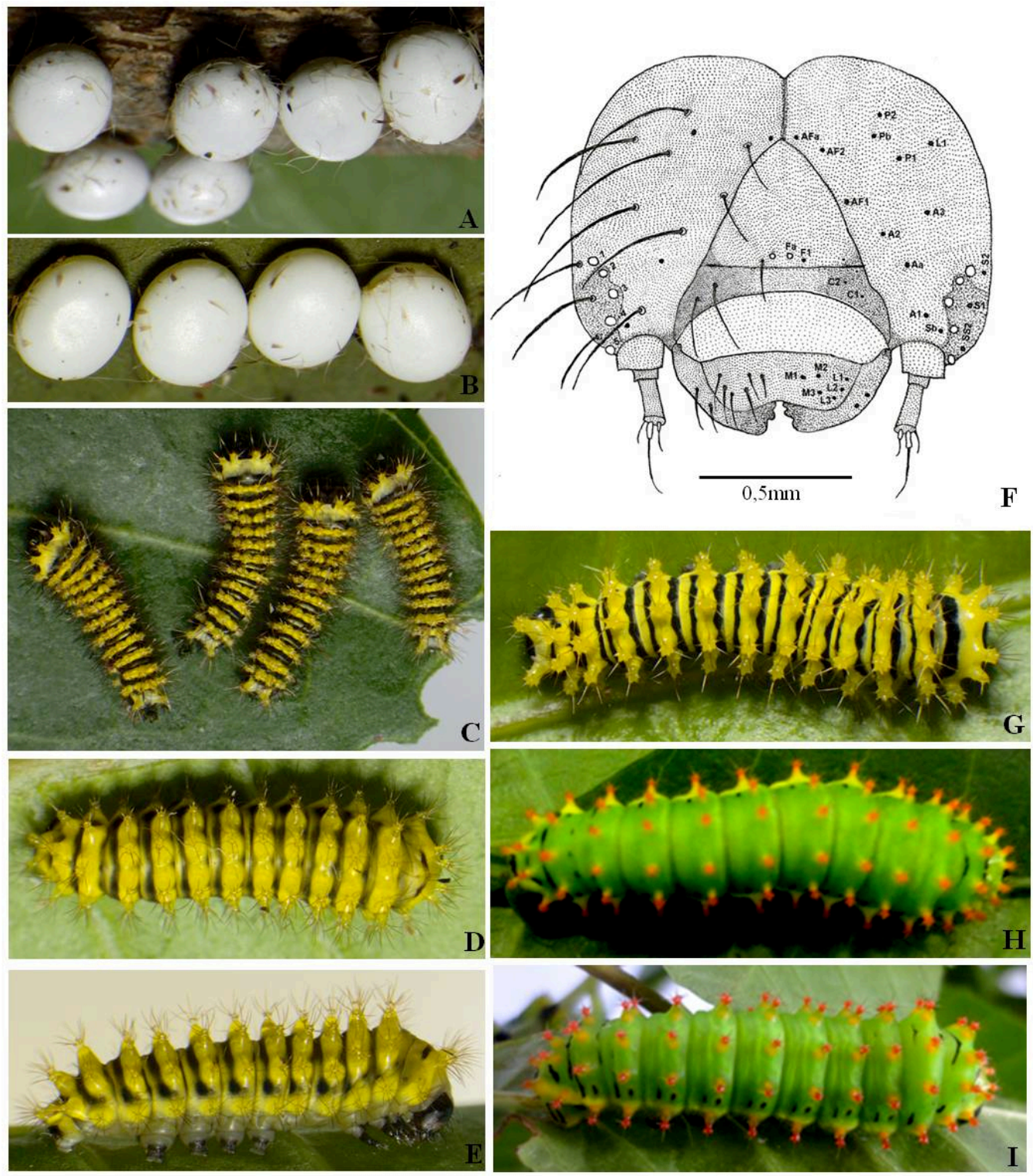
pernas castanhas; escolos com ápice laranja rosado e base amarela; pontos pretos similares aos espiráculos em T2-T3; tegumento dorsolateral verde podendo apresentar linhas pretas pontilhadas posteriores aos escolos; linha lateral amarela acompanhando a base dos escolos; porção láteroventral esverdeada. Abdome segue mesmo padrão geral do tórax; pontos pretos posteriores similares aos espiráculos em A1-A8; segmentos A8A10 com linha lateral amarela intumescida acima do larvópodo anal; larvópodos A3-6 com placas laterais esverdeadas; larvópodo anal com borda posterior amarelada e ornamentação lateral preta triangular. Presença de cerdas castanhas translúcidas distribuídas na cabeça, placa protorácica, pernas, escolos e placas dos larvópodos. Espiráculos pretos, T1 e A8 maiores que A1-A7 (Figura 2H; 2I).

Quarto ínstar. Comprimento total em repouso de 41,4 $\pm 1,2 \mathrm{~mm}(\mathrm{~N}=20)$. Cápsula cefálica largura máxima $4 \pm 0,1 \mathrm{~mm}(\mathrm{~N}=22)$. Cabeça verde com sutura epicranial, área adfrontal, clípeo e áreas laterais pretas. Tórax com placa protorácica esverdeada e pernas castanho esverdeadas; escolos com ápice laranja e base amarela; tegumento dorsolateral verde com redução da pigmentação de linhas pretas posteriores aos escolos; linha lateral esbranquiçada acompanhando a base dos escolos; porção láteroventral pubescente (cerdas esbranquiçadas) fornecendo aspecto acinzentado ao tegumento verde. Abdome segue mesmo padrão geral do tórax; segmentos A8-A10 com linha lateral intumescida verde limão acima do larvópodo anal; larvópodos A3-6 com placas laterais esverdeadas; larvópodo anal com borda posterior amarelada e ornamentação lateral preta triangular. Presença de cerdas castanhas translúcidas distribuídas na cabeça, placa protorácica, pernas, escolos e placas dos larvópodos. Espiráculos alaranjados (Figura 3A).

FIGURA 3: Rothschildia aurota speculifera. (A) Larva de 4 ínstar, vista dorsal. (B) Larva de 5 ínstar, vista dorsal. (C) Larva de 5 ínstar, vista lateral. (D) Larva de 5o ínstar, vista ventral. (E) Larva de 5o ínstar, detalhe dos segmentos abdominais A6-A10. (F) Casulo em folha de Schinus terebinthifolius.
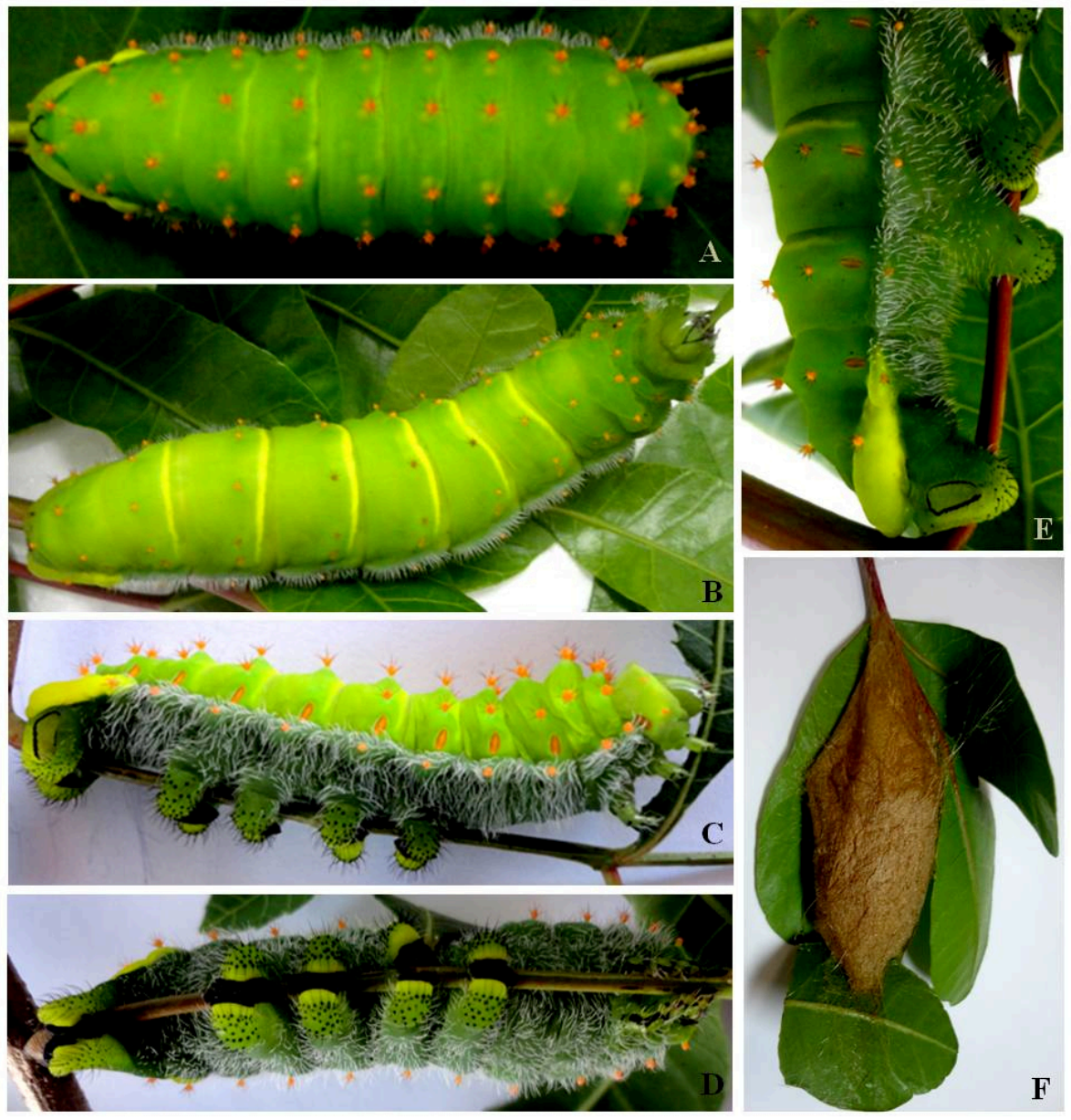
Quinto ínstar. Comprimento total em repouso de $76,4 \pm 2,4 \mathrm{~mm}(\mathrm{~N}=20)$. Cápsula cefálica medindo 5,9 $\pm 0,4 \mathrm{~mm}(\mathrm{~N}=20)$. Cabeça verde com sutura lateral adfrontal e estemas ventrais pretos, mandíbulas castanho claras, labro esverdeado com manchas pretas. Tórax e abdome seguem padrão similar ao descrito no ínstar anterior, mas com pernas verdes e a porção láteroventral mais pubescente (cerdas acinzentadas) (Figura 3B; 3C; 3D; 3E).

\section{Identificação morfométrica dos ínstares.} As medidas da largura da cápsula cefálica de $R$. $a$. speculifera apresentaram uma razão de crescimento $(\mathrm{K})$ igual a 1,4 mm (Tabela 1).

TABELA 1: Média e desvio padrão da largura das cabeças $(\mathrm{mm})$ e razão de crescimento $(\mathrm{K})$ entre os cinco ínstares de Rothschildia aurota speculifera.

\begin{tabular}{cccc}
\hline Ínstar & $\mathbf{N}$ & LM e DP (mm) & K \\
\hline I & 22 & $1,29 \pm 0,12$ & - \\
II & 22 & $1,85 \pm 0,08$ & 1,43 \\
III & 26 & $2,67 \pm 0,10$ & 1,43 \\
IV & 23 & $4 \pm 0,14$ & 1,45 \\
V & 20 & $5,92 \pm 0,38$ & 1,46 \\
\hline
\end{tabular}

$\mathrm{N}$ : número de indivíduos; LM: Largura média da cabeça; DP: Desvio padrão; mm: milímetros; K: Razão de crescimento da cabeça.

\section{Estágio pupal}

Casulo. Bem estruturado, fortificado por uma parede densa de seda. Aspecto fusiforme, presença de abertura anterior com fios organizados frouxamente para passagem do adulto. Base de fixação difusa com pedúnculo enrolado distalmente no pecíolo da folha anexando parcialmente folíolos à parede externa do casulo. Coloração marrom claro dourado. Largura $23,3 \pm 1,1 \mathrm{~mm}$, comprimento $73,8 \pm 5,4 \mathrm{~mm}(\mathrm{~N}=20)$ (Figura 3F).

Pupa. Adéctica e obtecta; oval estreitando posteriormente a partir de A6; tegumento corporal levemente rugoso desprovido de cerdas e tubérculos, cutícula opaca, marrom-avermelhada. Apêndices firmemente unidos à parede do corpo. Fêmea: Largura $17 \pm 8,2 \mathrm{~mm}$, comprimento 40,1 $\pm 1,9 \mathrm{~mm}(\mathrm{~N}=7)$. Macho: Largura $14 \mathrm{~mm}$, comprimento $30 \mathrm{~mm}(\mathrm{~N}=1)$. Cabeça: Antenas curvadas para a região ventral do corpo com as pectinas marcadas. Olho elíptico esculturado adjacente ao frontoclípeo e à antena. Frontoclípeo subretangular, delimitado lateralmente pelos olhos e pelas mandíbulas. Sutura frontoclipeal não evidente. Sutura epicraniana e frontal ausente. Labro triangular, posterior ao frontoclípeo entre as mandíbulas. Maxilas abaixo do labro entre as pernas protorácicas (Figura 4A; 4B; 4C).

FIGURA 4: Rothschildia aurota speculifera. (A) pupa fêmea, vista ventral. (B) pupa fêmea, vista dorsal. (C) pupa fêmea, vista lateral. $A$ segmento abdominal, $F c$ frontoclípeo, $M d$ mandíbula, $L b$ labro, $M x$ maxila, $P$ perna, $A t$ antena, $A A$ asa anterior, $A P$ asa posterior, Ep espiráculo, $\mathrm{Cm}$ cremaster.

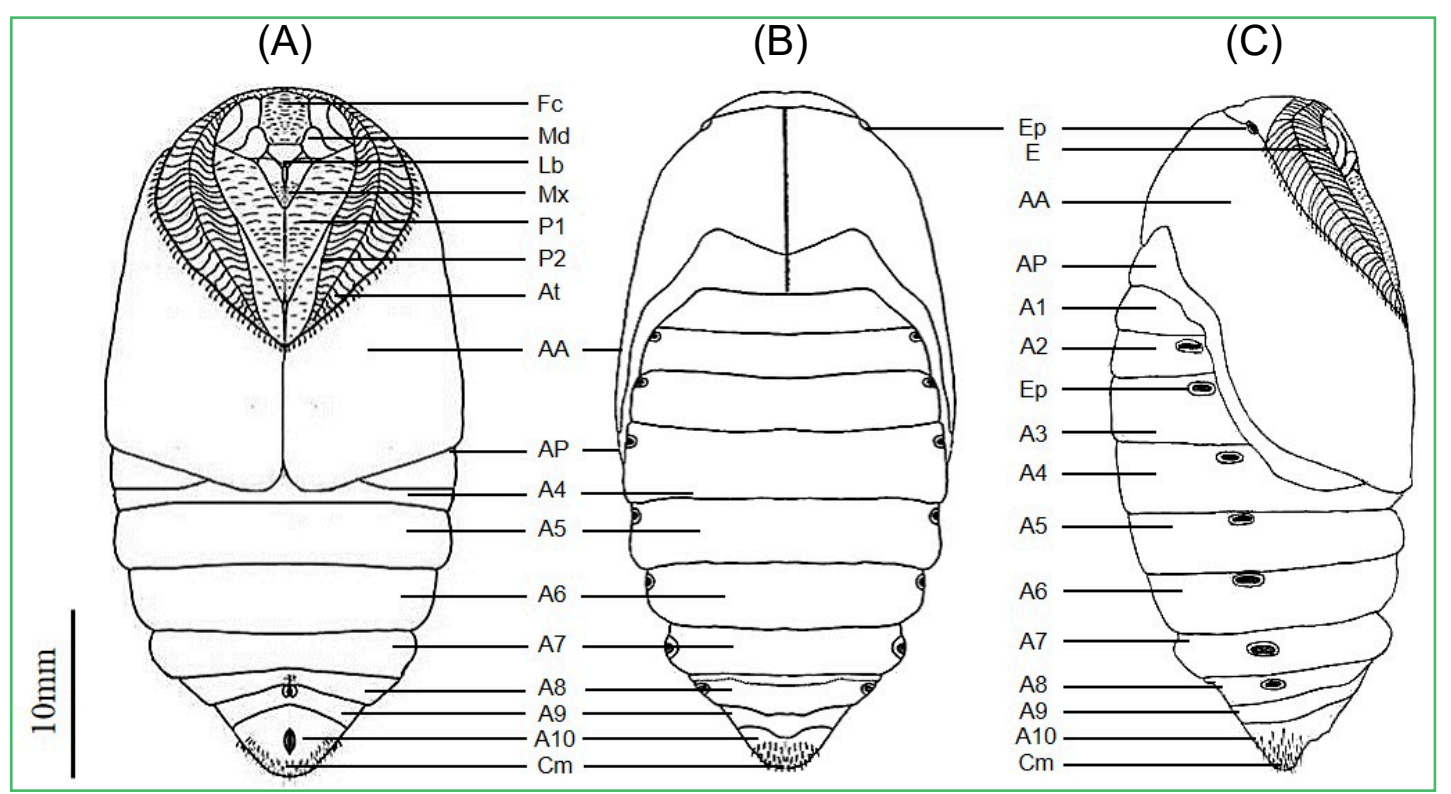


Tórax: Linha ecdisial mediana visível dorsalmente, segmentos torácicos visíveis em vista lateral e dorsal, ocultos ventralmente pelas asas. Pernas protorácicas situadas entre as maxilas e pernas mesotorácicas. Pernas mesotorácicas situadas entre as margens laterais das pernas protorácicas e antenas. Pernas e asas metatorácicas ocultadas por asas mesotorácicas. As pernas possuem tegumento liso (Figura 4A; 4B; 4C). Abdome: Dez segmentos abdominais, espiráculos visíveis de $\mathrm{A} 2$ a $\mathrm{A} 8$, assim como entre a cabeça e a asa anterior; abertura genital feminina possui dois sulcos ventrais contíguos entre A8-A9, na porção posterior de A8 e anterior de A9, abertura genital masculina (não ilustrada) estrutura elipsoide ocupando a porção mediana de A9 formada por orifício único em forma de fenda entre dois lobos convexos; abertura anal semelhante a uma fenda, localizada em A10 na porção mediano posterior; cremaster pouco diferenciado com porção terminal A10 pouco oval em vista lateral, várias cerdas rígidas com ápice levemente curvo (Figura 4A; 4B; 4C).

\section{Discussão}

\section{Ciclo de vida e comportamento}

Em relação às plantas hospedeiras conhecidas para as espécies de Rothschildia, há uma grande variedade de famílias botânicas envolvidas, um comportamento comum em Saturniidae presente em outros gêneros e subfamílias (COSTA LIMA, 1950; NUNES et al., 2004; SPECHT et al., 2006a; 2006b; 2007b; 2009; 2011; DUARTE et al., 2012). Atualmente, na base de dados Hosts (2020), são listadas 12 famílias e 22 espécies como plantas hospedeiras para $R$. aurota no Brasil: Anacardium occidentale L., Spondias cytherea Sonn., Spondias mombin L., S. terebinthifolius (Anacardiaceae); Annona sp., Rollinia mucosa (Jacq.) Baill. (Annonaceae); Bambusa sp. (Poaceae); Casearia sylvestris Sw. (Flacourtiaceae); Cephalanthus glabratus (Spreng.) K.Schum. (Rubiaceae), Chorisia speciosa A. St.-Hil. (Bombacaceae); Citrus sp., Zanthoxylum rhoifolium Lam. (Rutaceae); Ilex paraguariensis A. St.-Hil. (Aquifoliaceae); Joannesia princeps Vell., Manihot esculenta Crantz, Ricinus communis L., Sapium aucuparium Willd. (Euphorbiaceae);
Lonicera caprifolium L., Lonicera periclymenum L., Lonicera semenovii Regel (Caprifoliaceae); Morus alba L. (Moraceae), Prunus persica (L.) Batsch (Rosaceae). Costa Lima (1950) também cita Manihot utilissima Pohl. (Euphorbiaceae) como hospedeira de $R$. aurota. No momento, $R$. a. speculifera foi registrada apenas em $S$. terebinthifolius no município de Cruz das Almas, BA, que também abriga outras espécies listadas como hospedeiras.

$\mathrm{Na}$ oviposição, em relação ao número de ovos obtidos de uma única fêmea, há informações na literatura para $R$. jacobaeae com 244 ovos e para duas fêmeas de $R$. $h$. betis com 282 e 308 ovos, sendo que estas apresentaram comportamentos distintos, ou seja, a postura de 308 ovos foi fracionada em quatro dias de oviposição, 53\%-29\%-11\%-7\%. Entretanto, em ambos os casos notou-se a eclosão de larvas de primeiro ínstar em dias consecutivos, para $R$. zacateca, de uma única fêmea foram obtidos 160 ovos, um número significativamente menor quando comparado com as outras espécies (URBAN; OLIVEIRA, 1972; OLIVEIRA; URBAN, 1987; AMARILLO-S; WOLFE, 1997). Para $R$. a. speculifera foram obtidos 285 ovos em dois dias de oviposição e o comportamento foi similar a $R$. h. betis, ovipositados em fileiras e aglomerados irregulares, os ovos foram cimentados no substrato e a eclosão de larvas ocorreu em três dias consecutivos (OLIVEIRA; URBAN, 1987). Em relação à duração do estágio de ovo, a variação em $R$. a. speculifera foi de 12-14 dias, em $R$. jacobaeae foi observado o mínimo de 16 dias na primavera e nove dias na geração de verão, em $R$. h. betis 16 dias na geração outono-inverno e em $R$. zacateca foram observados 18 dias (URBAN; OLIVEIRA, 1972; AMARILLO-S; WOLFE, 1997).

O estágio larval de $R$. a. speculifera corroborou os cinco ínstares larvais observados em outras espécies de Saturniinae como R. jacobaeae, R. h. betis e R. zacateca e B. licharbas (URBAN; OLIVEIRA, 1972; OLIVEIRA; URBAN, 1987; AMARILLO-S; WOLFE, 1997; ROUGERIE; ESTRADEL, 2008). O estágio larval de $R$. a. speculifera durou entre 34-39 dias, sendo somado ao quinto ínstar dois dias para confecção do casulo, o período de pré-pupa não foi determinado, portanto, foi somado ao estágio de pupa. De acordo com Urban e 
Oliveira (1972), as mudanças morfológicas significativas que determinam a pré-pupa, chamada pelos autores de "larva inativa", foram observados em $R$. jacobaeae somente após a confecção completa do casulo. Em $R$. jacobaeae o estágio larval, desde a eclosão até a confecção completa do casulo, durou 43 dias no verão e 42 na geração de primavera, em $R$. h. betis o tempo de eclosão até o início da confecção do casulo foi de 41 dias no verão e 52 dias na geração outono-inverno (URBAN; OLIVEIRA, 1972; OLIVEIRA; URBAN, 1987). Para $R$. zacateca Amarillo-S e Wolfe (1997) não citam a duração do primeiro ínstar e apresentam 27 dias para o quinto ínstar, desta forma, somando o período do segundo ao quinto, são relatados ao todo 55 dias, apresentando a maior discrepância entre as espécies citadas. O quinto ínstar de $R$. a. speculifera, que é o mais longo, durou entre 11-16 dias, similar a $R$. jacobaeae 14-17 dias, para $R$. h. betis é citado apenas o período de alimentação de 11 dias no quinto ínstar (URBAN; OLIVEIRA, 1972; OLIVEIRA; URBAN, 1987).

\section{Diapausa}

Saturniidae pode apresentar um longo período de duração no estágio pupal, com emergências sincronizadas em uma determinada época do ano, por exemplo, em $A$. aidae (Arsenurinae) o estágio pupal dura 339 dias, tratase de uma espécie univoltina com diapausa obrigatória, onde os estágios de ovo e larval duram ao todo 15 dias, e a emergência dos adultos ocorre em duas semanas durante o auge da estação seca no bioma Cerrado no Mato Grosso, Brasil (FURTADO, 2004; GULLAN; CRANSTON, 2012). Entretanto, na literatura histórica, May (1923) forneceu as primeiras informações sobre a variação do período pupal para duas espécies de Rothschildia no Brasil, caracterizando a diapausa pupal em $R$. arethusa (citada como Rothschildia speculum) e em Rothschildia sp. (citada como similar a Rothschildia betis (Walker, 1855)), para $R$. arethusa o autor citou a variação do estágio pupal entre 3-6-9-12 e 15 meses, entretanto, para Rothschildia sp., uma pupa fêmea obtida de larva madura se manteve no estágio pupal por 19 meses, este período corresponde ao mais próximo do resultado obtido para a duração máxima da diapausa em $R$. a. speculifera, que foi de aproximadamente 21 meses (632 dias). Zamith e Mariconi (1962) também acompanharam o estágio pupal de $R$. arethusa obtido de larvas de último ínstar e do total de 34 pupas (11 machos, 22 fêmeas e 1 de sexo indefinido). A variação observada para nove machos foi entre 24-51 dias e para 21 fêmeas 25-49 dias, entretanto, dois machos entraram em diapausa pupal longa de 276 e 433 dias, uma fêmea com 253 dias e um espécime de sexo indefinido, 263 dias. Dos trabalhos realizados com biologia de Rothschildia, Urban e Oliveira (1972) acompanharam em laboratório três gerações de R. jacobaeae na região sul do Brasil, registrando variação de 22-130 dias no estágio pupal, os autores observaram ausência de diapausa na prépupa, sendo que este período durou ao todo quatro dias, provavelmente um período similar deve ocorrer em $R$. a. speculifera. Em B. licharbas (Saturniinae), 50\% dos indivíduos em estágio pupal tiveram emergência de adultos com variação 1-3 meses, sendo que o restante foi considerado pelos autores como diapausantes que emergiram após completarem 11-12 meses de pupa (ROUGERIE; ESTRADEL, 2008).

Analisando as emergências de machos e fêmeas de R. a. speculifera em relação a quatro estações do ano e as respectivas variações de temperatura e umidade, o maior número de emergências $(\mathrm{N}=24)$ ocorreu no verão 2018, quando foi registrada a temperatura média $26,91^{\circ} \mathrm{C}$ e UR $51,92 \%$, o outono 2018 foi o segundo período em número de emergências $(\mathrm{N}=19)$, completando $61,4 \%$ do total, em temperatura média $23,98^{\circ} \mathrm{C}$ e UR $66,08 \%$, período do experimento que apresentou a maior umidade relativa. Entretanto, $R$. $a$. speculifera também teve emergências no inverno 2018 $(\mathrm{N}=10)$, com a menor temperatura média $18,36^{\circ} \mathrm{C}$ e na primavera $2018(\mathrm{~N}=7)$, com a menor média de UR 42,52\% (Figura 1), desta forma, as emergências provavelmente não possuem correlação com os dados abióticos. Albertoni et al. (2018) apresentaram análise de fenologia das espécies de Saturniidae coletadas na Estação Biológica de Boraceia (EBB), Salesópolis, São Paulo, entre 1942 e 2013, os autores forneceram dados para seis espécies de Rothschildia, sendo que adultos de cinco espécies não foram coletados na EBB entre maiojulho, destes, $R$. a. speculifera não foi coletada entre abril-julho. Os dados apresentados por Albertoni et al. (2018) podem sugerir uma diapausa pupal para algumas 
espécies de Rothschildia na EBB durante os meses mais frios, que têm as mínimas mais baixas no município de Salesópolis entre junho-julho-agosto $\left(14^{\circ} \mathrm{C}-13^{\circ} \mathrm{C}-14^{\circ} \mathrm{C}\right)$ (CLIMATEMPO; 2020). A diapausa de inverno tem sido considerada em Saturniidae, por exemplo, em espécies de Automeris Hübner, [1819] (Hemileucinae) (SPECHT et al., 2006b). As médias climatológicas observadas para o município de Cruz das Almas entre junho-julho-agosto $2018\left(22,6^{\circ} \mathrm{C}-22^{\circ} \mathrm{C}-22,6^{\circ} \mathrm{C}\right)$ também correspondem aos meses mais frios, neste mesmo período, também se obteve as mínimas mais baixas $\left(18,45^{\circ} \mathrm{C}-17,80^{\circ} \mathrm{C}\right.$ $18,33^{\circ} \mathrm{C}$ ), entretanto, as emergências de $R$. a. speculifera no ano de 2018 ocorreram em todos os meses exceto agosto-setembro-outubro $\left(22,6^{\circ} \mathrm{C}-23,62^{\circ} \mathrm{C}-25,1^{\circ} \mathrm{C}\right)$, e todas as emergências de inverno se concentraram no mês de julho $(\mathrm{N}=10)$, que foi o mês mais frio de 2018 .

Specht et al. (2012) registraram diapausa pupal facultativa em Dirphia dolosa Bouvier, 1929 (Hemileucinae) a partir de estudo em campo comparando duas agregações de larvas, sendo que uma delas obteve maior tamanho e peso no estágio pupal (ambos os sexos), resultando em diapausa pupal. Os autores julgam que fatores nutricionais podem estar envolvidos, pois, de acordo com os resultados apresentados por Liu et al. (2010) com Helicoverpa armigera (Hübner, [1809]) (Noctuidae), a diapausa pupal demanda alto custo energético para suportar variações ambientais e apontam para a qualidade da planta hospedeira como fator que determina o peso e o número de pupas que podem entrar em diapausa. Os fatores nutricionais também podem estar envolvidos na diapausa pupal de $R$. a. speculifera, mas no presente estudo não puderam ser avaliados, pois não foi registrada a pesagem das pupas, e as medidas apresentadas foram obtidas de exemplares sacrificados para estudo morfológico. Entretanto, a planta hospedeira S. terebinthifolius pode ter contribuído de forma diferenciada na nutrição das larvas. De acordo com Gullan e Cranston (2012), um dos principais fatores que induzem ou encerram a diapausa em insetos herbívoros corresponde à qualidade da alimentação e à presença de determinados compostos secundários encontrados nas plantas hospedeiras. Schinus terebinthifolius é uma essência florestal nativa do Brasil, com ampla distribuição geográfica e plasticidade ecológica encontrada em várias fitofisionomias em diferentes altitudes, sendo explorada comercialmente em função das suas propriedades fitoquímicas medicinais e alimentícias (LENZI; ORTH, 2004). Durante o experimento, planta fresca foi fornecida constantemente, entretanto, no quinto ínstar pode ter ocorrido competição alimentar, pois houve uma variação de cinco dias na duração deste ínstar. Desta forma, um novo experimento com diferentes tratamentos, variáveis abióticas controladas, sexagem, pesagem das pupas e a testagem das várias plantas hospedeiras relatadas para $R$. a. speculifera pode elucidar melhor a questão da sua diapausa pupal.

\section{Morfologia do ovo}

Para determinar a forma do ovo é fundamental a identificação da área micropilar e consequentemente do seu eixo micropilar (eixo polar), que pode ser paralelo ou perpendicular ao substrato (ROUGERIE; ESTRADEL, 2008; SPECHT et al., 2009; 2011; 2012; ALBERTONI; DUARTE, 2015; MORAES et al., 2017). Ovos de Saturniidae podem variar quanto ao número, textura, coloração e forma, e, de acordo com Moraes et al. (2017), a forma achatada é a mais conhecida e registrada na literatura para vários gêneros de Hemileucinae, Ceratocampinae, Arsenurinae e Saturniinae, desta forma, os autores sugerem que o estado achatado do ovo pode representar um caráter plesiomórfico para o grupo. Entretanto, também citam variações dentro de uma mesma subfamília, nesse caso em Hemileucinae, que também possui ovos descritos como esféricos. Nos trabalhos realizados com Leucanella Lemaire, 1969, Periga Walker, 1855 e Dirphia Hübner, [1819] (Hemileucinae) (SPECHT et al., 2009; 2011; 2012; GONÇALVES et al., 2020), é notável que o eixo micropilar é perpendicular ao substrato e um pouco maior que o equatorial, resultando em uma forma esferoide oval, sendo que, em Periga e Dirphia, a área micropilar é diferenciada por uma leve depressão do cório, fornecendo aspecto côncavo, que ainda em Dirphia é marcada por coloração mais escura do exocório (SPECHT et al., 2011; 2012; GONÇALVES et al., 2020). Em Hylesia Hübner, [1820] (Hemileucinae), a oviposição é feita em grupos sobrepostos, formando um aglomerado de ovos protegidos por uma densa camada de cerdas, e a forma do ovo é considerada pelos autores 
como subcilíndrica, com extremidades arredondadas e com área micropilar em uma das extremidades (SPECHT et al., 2006a; 2007a). Na literatura os ovos considerados achatados possuem área micropilar pouco diferenciada, na maioria, visível apenas em microscopia eletrônica de varredura e geralmente o eixo micropilar é paralelo ao substrato (ROUGERIE; ESTRADEL, 2008; ALBERTONI; DUARTE, 2015; MORAES et al., 2017). Esses ovos têm sido chamados de esférico levemente alongado em $B$. licharbas (Saturniinae) (ROUGERIE; ESTRADEL, 2008), elipsoide e achatado em $A$. fallax (Ceratocampinae) (ALBERTONI; DUARTE, 2015) e elipsoide achatado lateralmente em Gamelia anableps (C. Felder \& R. Felder, 1874 (Hemileucinae) (MORAES et al., 2017). Outro estado para o ovo achatado é apresentado para o gênero Automeris, com eixo micropilar perpendicular ao substrato e área micropilar diferenciada com superfície côncava e coloração mais escura, semelhante aos ovos de Dirphia, entretanto, são denominados pelos autores como ovos subcilíndricos levemente achatados longitudinalmente (SPECHT et al., 2006b; 2007b). Desta forma, classificou-se os ovos de $R$. a. speculifera como achatados, esféricos levemente alongados, pois possuem eixo micropilar paralelo ao substrato, micrópila é pouco diferenciada, exocório esbranquiçado, opaco, esculturado em uma rede densa de células contíguas, portanto, os ovos de $R$. a. speculifera são semelhantes aos de B. licharbas (Saturniinae) (ROUGERIE; ESTRADEL, 2008). Os ovos R. $a$. speculifera diferem significativamente dos de $R$. jacobaeae e $R$. h. betis, pois os autores citam a presença de uma área micropilar preta bem evidente (URBAN; OLIVEIRA, 1972; OLIVEIRA; URBAN, 1987). Em $R$. zacateca os autores citam a forma arredondada achatada lateralmente, área micropilar não foi mencionada (AMARILLO-S; WOLFE, 1997). Quanto ao tamanho do ovo, comparando o maior diâmetro, $R$. jacobaeae e $R$. zacateca apresentaram $2,0 \mathrm{~mm}$ e $R$. $h$. betis $2,1 \mathrm{~mm}$, ou seja, menores que $R$. a. speculifera com $2,4 \pm 0,1 \mathrm{~mm}$.

\section{Morfologia do estágio larval}

De acordo com Moraes et al. (2017), em Saturniidae a quetotaxia de primeiro ínstar para o tórax e abdome é muito variável, pois cerdas primárias e secundárias podem estar presentes e também dispostas em calazas e escolos. Entretanto, a quetotaxia da cabeça tem se mostrado mais estável, portadora de poros e cerdas primárias com distribuição similar entre as subfamílias Saturniinae, Hemileucinae e Ceratocampinae (ROUGERIE; ESTRADEL, 2008; ALBERTONI; DUARTE, 2015; MORAES et al., 2017; GONÇALVES et al., 2020). Na vista frontal da cabeça de primeiro ínstar de $R$. a. speculifera não foram visualizados os poros MDa, La e Pa, microcerdas MD1, MD2 e MD3 identificados em B. licharbas (Saturniinae) (ROUGERIE; ESTRADEL, 2008). Em $R$. a. speculifera o poro Aa está entre a triangulação das cerdas A1, A2 e A3, este poro não foi identificado em $B$. licharbas. Entretanto, Rougerie e Estradel (2008) apontam a possibilidade de Aa representar o poro visualizado acima da cerda AF1, contudo, este poro tem sido considerado como Pa para Ceratocampinae e Hemileucinae (ALBERTONI; DUARTE, 2015; MORAES et al., 2017; GONÇALVES et al., 2020). As microcerdas (MD1, MD2 e MD3) também foram identificadas em Ceratocampinae e Hemileucinae assim como os poros MDa e La (ALBERTONI; DUARTE, 2015; MORAES et al., 2017; GONÇALVES et al., 2020). Em $R$. a. speculifera a cerda S3 não foi visualizada em vista frontal, esta cerda tem base de inserção posterior, e na vista frontal pode aparecer parcialmente em alguns grupos de Saturniidae (ROUGERIE; ESTRADEL, 2008; ALBERTONI; DUARTE, 2015; MORAES et al., 2017; GONÇALVES et al., 2020). Nas peças bucais, o labro de $R$. a. speculifera não apresenta o poro Ma, seguindo o padrão encontrado nas espécies de Hemileucinae incluindo o arranjo das cerdas laterais e mediais (MORAES et al., 2017; GONÇALVES et al., 2020). A terminologia das cerdas da cabeça de primeiro ínstar tem mostrado alguma variação na literatura de Saturniidae. Rougerie e Estradel (2008) utilizam os termos ocelar "O" e subocelar "SO" para o grupo de cerdas estemal "S" e subestemal "SS", microcerdas do vértice "V" para o grupo de microcerdas dorsais "MD" e poros "Va" e "Ob" para os poros "MDa" e "Sb" (HINTON, 1946; STEHR, 1987; ALBERTONI; DUARTE, 2015; MORAES et al., 2017; GONÇALVES et al., 2020). Para as peças bucais, Albertoni e Duarte (2015) classificam as cerdas laterais do labro como "LA", de acordo com Hinton (1946), mas 
estas cerdas também têm sido nomenclaturadas como "L" (ROUGERIE; ESTRADEL, 2008; MORAES et al., 2017; GONÇALVES et al., 2020). As cerdas laterais e mediais do labro também apresentam divergências na literatura quanto à numeração, em $B$. licharbas e A. fallax as cerdas L1 e M2 são consideradas as mais próximas do anteclípeo, e as L3 e M3, as mais próximas da margem do lobo labral, de acordo com a terminologia de Hinton (1946), estas espécies também apresentam um par de poros medianos próximos às cerdas M1 denominados de poro Ma (ROUGERIE; ESTRADEL, 2008; ALBERTONI; DUARTE, 2015). Entretanto, em G. anableps e Dirphia moderata Bouvier, 1929 a numeração das cerdas laterais é invertida e a cerda M3 é considerada a mais próxima do anteclípeo (MORAES et al., 2017; GONÇALVES et al., 2020). Stehr (1987) ilustra sete cerdas e dois poros para o labro, mas não aplica nomenclatura. Desta forma, seguindo a terminologia de Hinton (1946) para o labro, $R$. a. speculifera segue o mesmo padrão de $B$. licharbas, mas com ausência de poro Ma. A forma geral da cabeça de primeiro ínstar de $R$. a. speculifera é arredondada com sutura epicranial equivalente à terça parte das suturas adfrontais, diferindo de B. licharbas, A. fallax, $G$. anableps e $D$. moderata, que possuem a sutura epicranial significativamente maior que as adfrontais, chegando a três vezes em $A$. fallax (ROUGERIE; ESTRADEL, 2008; ALBERTONI; DUARTE, 2015; MORAES et al., 2017; GONÇALVES et al., 2020).

Rothschildia a. speculifera se aproxima das medidas da cabeça de $R$. zacateca (AMARILLO-S; WOLFE, 1997) do primeiro ao quinto ínstar, mas, no tamanho corpóreo, a larva de quinto ínstar de $R$. a. speculifera se mostrou maior. A identificação dos ínstares larvais de $R$. a. speculifera pode ser dificultada quando utilizado apenas o padrão de coloração. $\mathrm{O}$ primeiro e segundo ínstares são muito similares, assim como o quarto é similar ao quinto, entretanto, o terceiro apresenta caracteres de transição entre segundo e quarto ínstar, padrão similar foi observado em $R$. zacateca (AMARILLO-S; WOLFE, 1997). Desta forma, a determinação mais segura corresponde a análise da razão de crescimento utilizando as medidas da maior largura da cápsula cefálica, sendo que em $R$. a. speculifera o crescimento médio $(\mathrm{K})$ foi igual a $1,4 \mathrm{~mm}$, valor dentro da faixa de tolerância $(1,1 \mathrm{~mm}$ a $1,9 \mathrm{~mm})$ da regra de Dyar (PARRA; HADDAD, 1989), confirmando cinco ínstares no estágio larval (Tabela 1).

\section{Morfologia da pupa}

As pupas de Saturniidae apresentam variações em determinadas estruturas, na cabeça as antenas podem apresentar pectinações levemente aparentes e flagelo marcado por uma linha simples de pequenos tubérculos em Saturniinae (R.jacobaeae e B. licharbas) (URBAN; OLIVEIRA, 1972; ROUGERIE; ESTRADEL, 2008) ou em linha dupla em Ceratocampinae (Adeloneivaia) (ALBERTONI; DUARTE, 2015). Nos Hemileucinae, tubérculos no flagelo ainda não foram identificados, entretanto, as pectinações podem se apresentar levemente marcadas e, apesar de não serem mencionadas pelos autores, são visíveis nas ilustrações de Hylesia metapyrrha (Walker, 1855) (SPECHT et al., 2007a), Automeris naranja Schaus, 1898 (SPECHT et al., 2007b), Leucanella viridescens (Walker, 1855) (SPECHT et al., 2009), Periga circumstans Walker, 1855 (SPECHT et al., 2011), D. dolosa (SPECHT et al., 2012) e em D. moderata, onde as pectinações são chamadas pelos autores de segmentação antenal marcada por estrias (GONÇALVES et al., 2020). Entretanto, em G. anableps (Hemileucinae), a descrição e ilustrações dos autores mostram a ausência de pectinações e tubérculos no flagelo (MORAES et al., 2017), desta forma, variações podem ocorrer dentro de uma mesma subfamília, contudo, o caráter ainda deve ser melhor estudado, incluindo análises de possível dimorfismo sexual, pois em algumas espécies, por exemplo, $G$. anableps, os adultos apresentam a antena claramente filiforme nas fêmeas e bipectinadas nos machos. As pupas de $R$. a. speculifera apresentam antenas com pectinações marcadas e ausência de tubérculos no flagelo em ambos os sexos, o mesmo foi observado para $R$. h. betis (OLIVEIRA; URBAN, 1987), diferindo de $R$. jacobaeae, com tubérculos presentes (URBAN; OLIVEIRA, 1972). Em $R$. a. speculifera, a extensão das antenas alcança a porção posterior final da perna mesotorácica, desta forma, as pernas ficam contidas entre as antenas, situação similar a $B$. licharbas (Saturniinae) (ROUGERIE; ESTRADEL, 2008). Contudo, em 
Hemileucinae as antenas se estendem até a porção mediana da perna mesotorácica em A. naranja (SPECHT et al., 2007b), L. viridescens (SPECHT et al., 2009) e $G$. anableps (MORAES et al., 2017), porém, em D. dolosa e D. moderata (SPECHT et al., 2012; GONÇALVES et al., 2020), as antenas são mais longas, aproximando-se da porção distal da perna mesotorácica. Em Ceratocampinae (ALBERTONI; DUARTE, 2015), A. fallax apresenta as antenas mais curtas, que se estendem até o terço basal da perna mesotorácica, esta condição também pode ser vista em Hemileucinae para $P$. circumstans (SPECHT et al., 2011).

No abdome as pupas de Saturniidae apresentam dimorfismo sexual em relação aos orifícios genitais, para $R$. a. speculifera, a fêmea possui dois sulcos ventrais contíguos entre A8-A9 e os machos possuem um único orifício na porção mediana de A9, muito similar a $B$. licharbas (Saturniinae) (ROUGERIE; ESTRADEL, 2008), esta condição geral parece ser estável em Saturniidae e tem sido relatada também para Ceratocampinae e Hemileucinae (ALBERTONI; DUARTE, 2015; MORAES et al., 2017; GONÇALVES et al., 2020).

Rothschildia a. speculifera apresenta cremaster pouco diferenciado, onde a terminal de A10 é levemente pronunciada pouco oval com presença de várias cerdas rígidas com ápice pouco curvo, semelhante ao cremaster descrito para $R$. jacobaeae (URBAN; OLIVEIRA, 1972); provavelmente em função de o empupamento acontecer no interior de um casulo de seda suspenso e fortemente estruturado. Em G. anableps e D. moderata, a larva empupa em um casulo frágil, mal estruturado e possui cremaster diferenciado por vários espinhos em forma de gancho (MORAES et al., 2017; GONÇALVES et al., 2020). Em espécies de saturnídeos que realizam o empupamento no solo, o cremaster pode apresentar a forma de um espinho bifurcado bem pronunciado, como em $A$. fallax (ALBERTONI; DUARTE, 2015). Quanto ao tamanho, para $R$. jacobaeae e $R$. $h$. betis, os autores citaram apenas o comprimento entre $27-35 \mathrm{~mm}$ e $35 \mathrm{~mm}$, respectivamente, que são similares às medidas de $R$. $a$. speculifera com $30 \mathrm{~mm}$ para o macho e $40,1 \pm 1,9 \mathrm{~mm}$ para fêmeas (URBAN; OLIVEIRA, 1972; OLIVEIRA; URBAN, 1987).
O gênero Rothschildia pode apresentar um casulo bem estruturado e a espécie $R$. aurota (Cramer, 1775), que no passado foi chamada de Bombyx brasileira, quando a criação de Bombyx mori Linnaeus, 1758 era pouco explorada no Brasil, $R$. aurota foi recomendada para criação em grande escala, visando a produção de seda (COSTA LIMA, 1950). Rothschildia a. speculifera apresenta casulo de aspecto fusiforme, diferindo da descrição do casulo de $R$. jacobaeae com porção anterior angulosa e a posterior arredondada, resultando em uma forma oval, mas compartilham a abertura anterior diferenciada por fios organizados frouxamente para passagem do adulto (URBAN; OLIVEIRA, 1972). Para $R$. h. betis, os autores citam um longo pedúnculo de $80 \mathrm{~mm}$ que é enrolado distalmente ao ramo da planta hospedeira, semelhante ao padrão encontrado em $R$. a. speculifera, e não mencionado para $R$. jacobaeae, contudo, o pedúnculo de $R$. $a$. speculifera se apresenta de diferentes tamanhos de acordo com a folha escolhida (URBAN; OLIVEIRA, 1972; OLIVEIRA; URBAN, 1987). Para R. zacateca, Amarillo-S e Wolfe (1997) descrevem o casulo como de forma irregular, e Wenczel e Naumann (2005) fornecem imagem em que é possível observar a ausência de pedúnculo e abertura anterior pouco diferenciada. Quanto ao tamanho, o casulo de $R$. a. speculifera com largura $23,3 \pm 1,1 \mathrm{~mm}$ e comprimento $73,8 \pm 5,4 \mathrm{~mm}$ se aproxima de $R$.h. betis com largura de $25 \mathrm{~mm}$ e comprimento $70 \mathrm{~mm}$ (OLIVEIRA; URBAN, 1987).

\section{Agradecimentos}

Ao Prof. Dr. Marcelo Duarte da Silva (Museu de Zoologia da USP, São Paulo, SP), pela prestimosa colaboração, fornecimento de bibliografia e consulta aos espécimes do acervo Lepidoptera MZUSP. Ao pesquisador Dr. Amabílio José Aires de Camargo (EMBRAPA - Cerrados, Planaltina, DF), pela identificação taxonômica de $R$. aurota.

\section{Referências}

ALBERTONI, F. F.; DUARTE, M. Immature stages of Adeloneivaia fallax (Lepidoptera: Saturniidae). Florida Entomologist, Lutz, v. 8 , n. 1 , p. $178-185,2015$. 
ALBertoni, F. F.; MIELKE, C. G. C.; DUARTE, M. Saturniid moths (Lepidoptera: Bombycoidea) from an Atlantic Rain Forest fragment in southeastern Brazil. Anais da Academia Brasileira de Ciências, Rio de Janeiro, v. 90, n. 3, p. 2827-2844, 2018.

AMARILlO-S, A. R.; WOLFE, K., L. Descripción del ciclo de vida y ampliación de ámbito de Rothschildia zacateca (Lepidoptera: Saturniidae). Tropical Lepidoptera Research, Gainesville, v. 8, n. 2, p. 71-74, 1997.

BRECHLIN, R.; MEISTER, F. Neue taxa der gattung Rothschildia Grote, 1896 (Lepidoptera: Saturniidae). Entomo-Satsphingia, Pasewalk, v. 5, n. 3, p. 13-37, 2012.

BRECHLIN, R.; MEISTER, F. Sechs neue taxa der gattung Rothschildia Grote, 1896 (Lepidoptera: Saturniidae). EntomoSatsphingia, Pasewalk, v. 6, n. 1, p. 14-22, 2013.

CLIMATEMPO. Climatologia - Salesópolis, SP. 2020. Disponível em $\quad<$ https://www.climatempo.com.br/climatologia/532/ salesopolis-sp>.

COSTA LIMA, A. Insetos do Brasil. $6^{\circ}$ Tomo. Lepidópteros. $2^{\circ}$ parte. Rio de Janeiro: Escola Nacional de Agronomia (Série Didática 8), 1950. $420 \mathrm{p}$.

DUARTE, M.; MARCONATO, G.; SPECHT, A.; CASAGRANDE, M. M. Lepidoptera. In: RAFAEL, J. A.; MELO, G. A. R.; CARVALHO, C. J. B.; CASARI, S.; CONSTANTIN, R. (Ed.). Insetos do Brasil: diversidade e taxonomia. Ribeirão Preto: Holos Editora, 2012. p. 625-682.

FURTADO, E. Automerula auletes (Eric-Schäffer, 1854) e seus estágios imaturos (Lepidoptera, Saturniidae, Hemileucinae). Lambillionea, Copenhagen, v. 102, n. 1, p. 110-112, 2002.

FURTADO, E. Almeidaia aidae Mielke \& Casagrande: seus estágios imaturos e notas taxonômicas (Lepidoptera, Saturniidae, Arsenurinae, Almeidaiini). Revista Brasileira de Zoologia, Curitiba, v. 21, n. 3, p. 663-669, 2004.

GARCÍA-BARROS, E.; MARTÍN, J. The eggs of European satyrine butterflies (Nymphalidae): external morphology and its use in systematics. Zoological Journal of the Linnean Society, London, v. 115, n. 1, p. 73-115, 1995.

GULLAN, P. J.; CRANSTON, P. S. Os insetos: um resumo de entomologia. 4 ed. São Paulo: Roca, 2012. 480 p.

GONÇALVES, G. A. S.; BARBOSA, F. S.; PALUCH, M. Biology and external morphology of the immature stages of Dirphia moderata Bouvier (Lepidoptera: Saturniidae: Hemileucinae) in Anacardium occidentale L. Brazilian Journal of Biology, São Carlos, v. 80, n. 1, p. 147-157, 2020.

HINTON, H. E. On the homology and nomenclature of setae of lepidopterous larvae, with some notes on the phylogeny of Lepidoptera. Transactions of the Royal Entomological Society of London, London, v. 97, p. 1-37, 1946.

HOSTS. A database of the World's Lepidopteran Hostplants. Saturniidae - Rothschildia aurota - Brazil - Hostplant. Natural History Museum (Ed.). 2020. Disponível em <https://www.nhm. ac.uk/our-science/data/hostplants/search/>.

INPN - INVENTAIRE NATIONAL DU PATRIMOINE NATUREL. Rothschildia aurota aurota (Cramer, 1775) - Data on distribution. Muséum National d'Histoire Naturelle (Ed.). 2020. Disponível em <https://inpn.mnhn.fr/espece/cd_nom/760981>.
LEMAIRE, C. Les Attacidae américains. The Attacidae of America (= Saturniidae). Attacinae. Neuilly-sur-Seine: Édition C. Lemaire, 1978. 238 p.

LEMAIRE, C. Saturniidae. In: HEPPNER, J. B. (Ed.). Atlas of Neotropical Lepidoptera. Vol. 5B. Checklist: Part 4B. Drepanioidea - Bombycoidea - Sphingoidea. Gainesville: Association of Tropical Lepidoptera \& Scientific Publishers, 1996. p. 28-49.

LENZI, M.; ORTH, A. I. Fenologia reprodutiva, morfologia e biologia floral de Schinus terebinthifolius Raddi (Anacardiaceae), em restinga da Ilha de Santa Catarina, Brasil. Biotemas, Florianópolis, v. 17, n. 2, p. 67-89, 2004.

LIU, Z.; GONG, P.; LI, D.; WEI, W. Pupal diapause of Helicoverpa armigera (Hübner) (Lepidoptera: Noctuidae) mediated by larval host plants: pupal weight is important. Journal of Insect Physiology, Oxford, v. 56, p. 1863-1870, 2010.

MAY, E. Observações sobre a duração da phase pupal de Rothschildia speculum (Mass. \& Weym.) e espécies congêneres. Archivos do Museu Nacional, Rio de Janeiro, v. 24, p. 349-351, 1923.

MORAES, S. S.; OTERO, L. S.; FREITAS, A. V. L. Natural history and comparative morphology of immatures of Gamelia anableps (C. Felder \& R. Felder) (Lepidoptera: Saturniidae, Hemileucinae). Neotropical Entomology, Londrina, v. 46, n. 4, p. 397-408, 2017. MOSHER, E. The classification of the pupae of the Saturniidae. Annals of the Entomological Society of America, Annapolis, v. 9, n. 2, p. 136-158, 1916.

NUNES, F. G.; PRESTES, A. S.; CORSEUIL, E. Mariposas do gênero Rothschildia (Lepidoptera, Saturniidae) registradas para o Rio Grande do Sul, Brasil. Biociências, Porto Alegre, v. 12, n. 1, p. 31-36, 2004.

OLIVEIRA, B., L.; URBAN, D. Contribuição ao conhecimento da biologia de Rothschildia hesperus betis (Lepidoptera, Saturniidae). Acta Biológica Paranaense, Curitiba, v. 16, n. 1-4, p. 67-76, 1987.

PARRA, J. R. P.; HADDAD, M. L. Determinação do número de ínstares de insetos. Piracicaba: Fealq, 1989. 49 p.

ROUGERIE, R.; ESTRADEL, Y. Morphology of the preimaginal stages of the African emperor moth Bunaeopsis licharbas (Maassen and Weyding): phylogenetically informative characters within the Saturniinae (Lepidoptera: Saturniidae). Journal of Morphology, Malden, v. 269, n. 2, p. 207-232, 2008.

SANTOS, F. L.; CASAGRANDE, M. M.; MIELKE, O. H. H. Saturniidae and Sphingidae (Lepidoptera, Bombycoidea) assemblage in Vossoroca, Tijucas do Sul, Paraná, Brazil. Anais da Academia Brasileira de Ciências, Rio de Janeiro, v. 87, n. 2, p. 843-860, 2015.

SIEWERT, R. R.; SILVA, E. J. E.; MIELKE, C. G. C. Saturniidae from Santa Catarina State, Brazil, with taxonomic notes (Lepidoptera). Nachrichten des Entomologischen Vereins Apollo, Frankfurt, v. 30, n. 4, p. 215-220, 2010.

SPECHT, A.; CORSEUIL, E.; BENEDETTI, A. J.; POLETTO, G.; FORMENTINI, A. C. Aspectos biológicos e morfológicos de Leucanella viridescens (Lepidoptera: Saturniidae: Hemileucinae). Zoologia, Curitiba, v. 26, n. 1, p. 25-31, 2009.

SPECHT, A.; FORMENTINI, A. C.; BENEDETTI, A. J. Biology and morphology of Molippa cruenta (Lepidoptera: Saturniidae) in the laboratory. Zoologia, Curitiba, v. 27, n. 3, p. 347-352, 2010. 
SPECHT, A.; FORMENTINI, A. C.; CORSEUIL, E. Biologia de Hylesia nigricans (Berg) (Lepidoptera, Saturniidae, Hemileucinae). Revista Brasileira de Zoologia, Curitiba, v. 23, n. 1, p. 248-255, 2006a.

SPECHT, A.; FORMENTINI, A. C.; CORSEUIL, E. Biologia de Automeris illustris (Walker) (Lepidoptera, Saturniidae, Hemileucinae). Revista Brasileira de Zoologia, Curitiba, v. 23, n. 2, p. 537-546, 2006b.

SPECHT, A.; FORMENTINI, A. C.; CORSEUIL, E. Biological aspects of Hylesia metapyrrha (Lepidoptera; Saturniidae; Hemileucinae), in laboratory. Brazilian Journal of Biology, São Carlos, v. 67, n. 1, p. 173-177, 2007a.

SPECHT, A.; FORMENTINI, A. C.; CORSEUIL, E. Biologia e aspectos morfológicos dos estágios imaturos de Automeris naranja Schaus (Lepidoptera, Saturniidae, Hemileucinae). Revista Brasileira de Zoologia, Curitiba, v. 24, n. 3, p. 537-545, $2007 \mathrm{~b}$.

SPECHT, A.; FRONZA, E.; COLOMBI, E. E.; FORMENTINI, A. C.; CORSEUIL, E. Aspects of the biology and morphology of Dirphia dolosa Bouvier, 1929 (Lepidoptera: Saturniidae: Hemileucinae). Biota Neotropica, Campinas, v. 12, n. 4, p. 21-28, 2012.

SPECHT, A.; LORINI, L. M.; FRONZA, E.; POLETTO, G. Biological aspects of Periga circumstans Walker, 1855 (Lepidoptera: Saturniidae: Hemileucinae) with larvae reared on khaki and mate-plant leaves. Brazilian Journal of Biology, São Carlos, v. 71, n. 4, p. 1015-1022, 2011.

STEHR, F. W. Order Lepidoptera. In: STEHR, F. W. (Ed.). Immature insects. Dubuque: Kendall/Hunt, 1987. p. 288-596.
URBAN, D.; OLIVEIRA, B., L. Contribuição ao conhecimento da biologia de Rothschildia jacobaeae (Lepidoptera, Saturniidae). Acta Biológica Paranaense, Curitiba, v. 1, n. 1-2, p. 35-49, 1972.

WENCZEL, B.; NAUMANN, S. New records for the genus Rothschildia Grote from Peru and surrounding countries (Lepidoptera: Saturniidae). Galathea, Berichte des Kreises Nürnberger Entomologen, Nürnberger, v. 21, supl. 16, p. 189201, 2005.

WOLFE, K. L.; BALCÁZAR-LARA, M. A. An illustrated description immature stages of Lonomia electra (Druce, 1886) (Lepidoptera: Saturniidae, Hemileucinae). Nachrichten des Entomologischen Vereins Apollo, Frankfurt, v. 15, n. 3, p. 383392, 1994.

ZAMITH, A. P. L.; MARICONI, F. A. M. Contribuição para o conhecimento do lepidóptero saturnídeo Rothschildia arethusa (Walker, 1855). Anais da Escola Superior de Agricultura Luiz de Queiroz, Piracicaba, v. 19, p. 389-396, 1962.

ZANUNCIO, T. V.; ZANUNCIO, J. C.; MEIRA, I. A.; ARAÚJO, F. S. Caracterização das fases larval e adulta de Dirphia avicula (Lepidoptera: Saturniidae) em folhas de Eucalyptus urophylla. Revista Árvore, Viçosa, v. 18, n. 2, p. 153-158, 1994.

ZENKER, M. M.; SPECHT, A.; FRONZA, E.; POLETTO, G.; MARCON, F.; FORMENTINI, A. C.; GEDOZ, M. Biology and life table of Dirphia araucariae (Lepidoptera: Saturniidae): a herbivore of potentially high impact on Araucaria angustifolia. Zoologia, Curitiba, v. 30, n. 2, p. 143-150, 2013. 